\title{
Martin Chalfie y la proteína verde fluorescente
}

\author{
Martin Chalfie and the green flourescent protein
}

\section{Zacarías Pereira Vega'}

Fecha de recepción: I de febrero del 2012

Fecha de aprobación: 8 de mayo del 2012

Pereira, Z. Martin Chalfie y la proteína

verde fluorescente. Tecnología en

Marcha. Vol. 25, N 4. Pág 86-9l

I Farmacéutico y químico. Profesor, Facultad de Farmacia de la Universidad de Costa Rica; estudiante de posgrado de la Maestría en Química Industrial. Teléfono: 25 I I-3560.

Correo electrónico: zacarias.pereira@ucr.ac.cr 


\section{Palabras clave}

GFP, Aequorea victoria, C. elegans, expresión heteróloga, PCR, promotor, fluoróforo.

\section{Resumen}

La historia de la proteína verde fluorescente (GFP) se inicia con Osamu Shimomura a principios de la década de 1960, con su descubrimiento de esta proteína a partir de extractos de la medusa Aequorea victoria. Sin embargo, es a principios de la década de 1990 que el neurobiólogo Martin Chalfie, aplicando técnicas de ingeniería genética, logra por primera vez la expresión heteróloga de la GFP en procariotas (Escherichia coli) y eucariotas (Caernohabditis elegans), a partir de un clon del gen de la medusa que codifica a la GFP, preparado por Douglas Prasher.

Además de fluorescer en verde, los resultados de este trabajo también demostraron que no se requiere ningún cofactor o enzima de la medusa para su expresión o para la formación misma del fluoróforo. Asimismo, Chalfie propuso que la GFP podría utilizarse para el marcaje de células en animales vivos o para el etiquetado de proteínas.

Los resultados de Chalfie dispararon las investigaciones sobre esta proteína y en la actualidad se usa en diversos campos, tales como la biotecnología, la biología del desarrollo, la química ambiental y la medicina. En la medicina está ayudando a dilucidar los mecanismos celulares por los que se producen muchas enfermedades. A Roger Tsien se le debe, entre otros aportes, la creación de diversas mutantes de la GFP.
Key words

GFP, Aequorea victoria, Caernohabditis elegans, heterology expression, PCR, promoter, fluorophore.

\section{Abstract}

The history of the green fluorescent protein (GFP) starts with Osamu Shimomura at the beginning of the 1960s, with his discovery from the extracts of the Aequorea victoria jellyfish. However, it is not until the beginning of the 1990s, that the neurobiologist Martin Chalfie, applying genetic engineering techniques, achieved for the first time the heterology expression of the GFP in prokaryotes (E. coli) and eukaryotes (Caernohabditis elegans), from a clone of the jellyfish's gen that codifies the GFP prepared by Douglas Prasher.

Besides fluorescing in green, the results from this work also demonstrated that it does not require any other cofactor or enzyme of the jellyfish for its expression or for the own forming of a fluorophore. At the same time, Chalfie proposed that the GFP could be used for the marking of cells on living animals or the tag of proteins.

Based upon these results, many scientists started working on research related to the GFP; actually this protein is used on different fields such as biotechnology, development biology, environmental chemistry and medicine. In the case of the latter, it has helped to elucidate the cellular mechanisms from which diseases are made of. Science owes Roger Tsien, amongst other contributions, the creation of different mutations of the GFP. 


\section{Antecedentes}

El premio Nobel de Química del 2008 fue otorgado a los científicos Osamu Shimomura (japonés, 1928), Martin Chalfie (norteamericano, 1947) y Roger Tsien (norteamericano de origen chino, 1952), por el descubrimiento y desarrollo de la proteína verde fluorescente (o GFP, del inglés Green Fluorescent Protein).

La GFP -junto con otra proteína de nombre aequorina- fue descubierta a principios de la década de 1960 por el químico Osamu Shimomura como consecuencia de sus estudios sobre bioluminiscencia, que lo llevaron a trabajar con tejidos de la medusa Aequorea victoria, un organismo bioluminiscente que habita en las aguas de la costa occidental de Norteamérica, la cual brilla en el borde exterior del paraguas cuando se mueve (Morise et al., 1974, Shimomura, 2005).

\section{Datos biográficos de Martin Chalfie}

Martin Chalfie es un neurobiólogo y profesor de la Universidad de Columbia. Chalfie nace en Chicago Illinois en 1947. Durante su educación secundaria no se siente muy atraído por los cursos estándares de ciencias y cuando entra a la Universidad de Harvard pierde la beca Searle por haber expresado inocentemente el no tener claro qué quería estudiar.

Ya en Harvard, luego de haberse visto atraído por las matemáticas, se decide finalmente por la bioquímica. Su primera experiencia en investigación la hace en el laboratorio de un profesor de esa casa de estudios, Klaus Weber, quien le asigna trabajar en el sitio activo de la enzima aspartato transcarbamilasa, pero los resultados del experimento fueron desalentadores y él interpretó la experiencia como un rotundo fracaso. Consecuentemente pensó que no había nacido para la investigación.

Se gradúa en 1969 y en 1970 entra a trabajar en un colegio de secundaria en Connecticut, dando clases de matemáticas y química. En este lugar conoce a la bióloga Barbara Beitch, quien lo contacta con un profesor de la Escuela de Medicina de la Universidad de Yale y lo insta para que se le dé una nueva oportunidad en investigación.

Estando ya ahí trabaja en el transporte de cloruro en la córnea de rana, y él mismo manifiesta que esta experiencia fue muy satisfactoria en muchos aspectos y logra su primera publicación. Ahora, con más confianza, decide ingresar al Departamento de Fisiología de la Universidad de Harvard y estudia con Bob Perlman la biosíntesis y secreción de catecolaminas.

De hecho, su tesis doctoral tuvo que ver sobre este tema, pero usando como modelo de estudio un feocromocitoma trasplantado en ratas, un tipo de tumor que crece anormalmente en las glándulas suprarrenales de los seres humanos (Chalfie, 1976a, Chalfie, 2009b).

Chalfie termina el doctorado en 1976 y en 1977 inicia el postdoctorado en el Laboratorio de Investigaciones Médicas del Centro de Biología Molecular de Cambridge, Inglaterra. Dicho laboratorio usaba como modelo de investigación el gusano transparente Caernohabditis elegans. La experiencia de cuatro años como postdoctorado fue muy constructiva y él mismo manifiesta que lo hizo el científico que es en la actualidad. En 1982 es contratado como profesor de la Universidad de Columbia (Davis, 2008).

\section{Clonación y expresión heteróloga de la GFP}

A finales de abril de 1989 Chalfie asiste a un seminario sobre organismos marinos bioluminiscentes, y es ahí donde escucha hablar por primera vez de la medusa Aequorea victoria y de la GFP extraída de ella. Él no termina de escuchar el seminario y lo abandona muy entusiasmado al imaginar lo que podía hacer si lograba incorporar la proteína en su gusano transparente, C. elegans. C. elegans es un nemátodo de I mm de longitud, hermafrodita (99,95\%), que se reproduce por huevos y vive de dos a tres semanas bajo condiciones controladas de laboratorio (Strange, 2006).

Para expresar la GFP en C. elegans (eucariota) y en Escherichia coli (procariota), Chalfie necesitaba el gen de la GFP, sin embargo, ya Douglas Prasher, un bioquímico de la Woods Hole Oceanographic Institution, estaba trabajando en ello. Luego de ponerse en contacto con él vía telefónica, deciden compartir información y trabajar juntos luego de que Prasher lograra clonar el gen que codificaba a la GFP.

Con fondos de la Sociedad Americana del Cáncer y empleando técnicas y procedimientos afines a la 
ingeniería genética y la biotecnología, Prasher logra clonar el gen que codifica a la GFP y también determina la secuencia de nucleótidos del gen.

Con esta información, y haciendo uso del código genético, obtiene la estructura primaria de la GFP, que corresponde a la secuencia de aminoácidos de la proteína. La proteína resultó tener 238 residuos de aminoácidos y una masa molar relativa de 26888 Daltons (Prasher et al., 1992).

En 1992, Chalfie retoma su interés por la GFP, luego de haber descuidado el asunto por un tiempo, y consigue el clon de la proteína que le fue finalmente facilitado por Prasher. Cuando el equipo de Chalfie recibe el clon de la GFP, tenía dos alternativas. La primera era cortar el gen con nucleasas de restricción y la segunda consistía en amplificarlo mediante una PCR (Reacción en Cadena de la Polimerasa).

Los fragmentos obtenidos por ambos procedimientos se incorporarían luego en un vector de expresión. En ese mismo periodo otros grupos científicos estaban intentando la expresión heteróloga de la GFP, pero no tuvieron éxito.

Estos grupos estaban usando nucleasas de restricción, pero al hacerlo se estaban llevando consigo ADN adicional no codificante de la medusa, que al incorporarlo en el vector de expresión interfería directamente en la transcripción.

Desde un inicio, el equipo de Chalfie trabajó en la segunda opción, aún con los riesgos inherentes al uso de la PCR que se sabe que puede inducir errores al introducir cambios de las bases nitrogenadas. En la actualidad, la PCR es una técnica muy utilizada y estos errores se han reducido en gran medida al usar versiones mejoradas de la enzima ADN polimerasa (Chalfie, 2009b, McPherson et al., 2006).

Luego de introducir el gen amplificado por PCR en un vector de expresión, usaron un promotor diferente para cada caso: para el bacilo E. coli se usó el promotor del fago T7 y para C. elegans el promotor constitutivo mec-7.

Los promotores son secuencias especiales de nucleótidos del ADN genómico que están muy cerca de los genes que regulan e indican el punto de inicio de la síntesis del ARN mensajero. El promotor posee los elementos de secuencias para reconocimiento por distintos factores de transcripción que hace que el ARN mensajero se exprese en determi- nados tipos celulares y no en otros. Ellos funcionan como un interruptor genético que indican en qué momento se activa el gen y facilitan la transcripción ya que favorecen el enlace de la ARN polimerasa al ADN (Alberts et al., 2008, Martín, 2005).

A continuación, el grupo de Chalfie logró expresar la GFP en ambos organismos, primero en E. coli y luego en C. elegans, lo cual se manifestaba mediante la fluorescencia verde característica de esta sustancia cuando eran expuestos a la luz ultravioleta, o a la luz azul, de un microscopio de fluorescencia. En la figura I se logra ver una placa de Petri, en cuyo lado izquierdo había bacterias control y al lado derecho bacterias a las cuales se les inoculó el plásmido de expresión y lograron fluorescer en verde.

Ambos experimentos eran sorprendentes, sin embargo, al usar el promotor del gen mec-7 en $C$. elegans, el cual se sabe que ayuda a codificar una proteína de nombre beta tubulina, que se expresa en mayor medida en solo seis neuronas del gusano - llamadas neuronas mecanosensoras-, garantizaba que la GFP se expresara en mayor grado en ese tipo de células. Como se puede observar en la figura 2, dos cuerpos celulares de estas neuronas fluorescen intensamente en verde.

simismo, el grupo de Chalfie demostró que las propiedades espectrales de un lisado de bacterias de $E$. coli que lograron expresar la GFP, eran exactamente las mismas que las de la GFP extraída y purificada a partir de la medusa A. victoria. Chalfie fue el primero en expresar la GFP en modelos de organismos procariotas y eucariotas, asimismo logró demostrar que no se requiere de cofactores o enzimas propios de la medusa para la expresión heteróloga de la GFP.

De la misma manera, Chalfie propuso que la GFP podía usarse para el marcaje de células en animales vivos y el etiquetado de proteínas. En cuanto al marcaje de células, las células que expresan la GFP se pueden seguir en vivo en el propio sitio de acción, o sea, como estar viendo una película solo que en tiempo real.

Los resultados de este trabajo fueron publicados en febrero de 1994 en la revista Science, lo cual disparó las investigaciones sobre esta proteína, que en la actualidad tiene usos y aplicaciones muy variados en distintas áreas de la ciencia, que van desde la biotecnología y la biología del desarrollo hasta la química ambiental y la medicina, entre otras. 


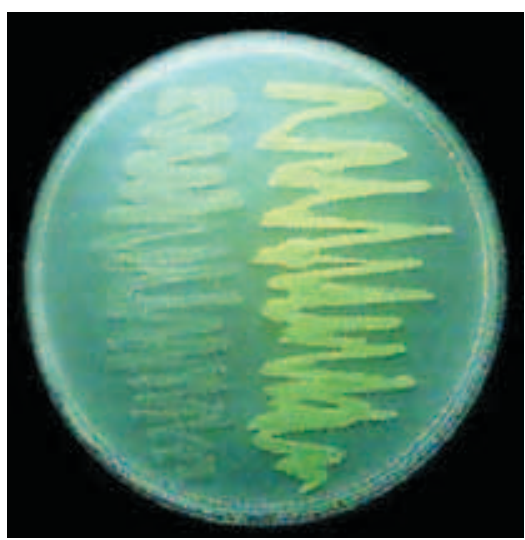

Figura I. Expresión de la GFP en E. coli. Fuente: Chalfie et al., 1994c. Con autorización de la revista Science y del autor.

Asimismo, a partir de este trabajo y de otros que diversos científicos lograron realizar a continuación, la GFP demostró presentar las siguientes ventajas como marcador biológico: es heredable, relativamente no invasiva, pequeña y monomérica, visible en los tejidos vivos y relativamente no tóxica (Chalfie, 2009b, Chalfie et al., 1994c, Lucas, 2009).

\section{Aspectos químicos y desarrollo de la GFP}

La GFP es una estructura monomérica que tiene forma de cilindro o barril, consiste de II cadenas beta antiparalelas y una hélice alfa que contiene al fluoróforo que se encuentra protegido en el centro del barril. El barril tiene una longitud de 42 angstroms y un diámetro de 24 angstroms.

Según la secuencia de aminoácidos de esta proteína, el fluoróforo está constituido por los aminoácidos 65,66 y 67 que corresponden a serina, tirosina y glicina, respectivamente. El fluoróforo recibe el nombre de 4-( $p$-hidroxibencilideno)imidazolidin-5-ona (Chalfie, 1995d, Cody et al., 1993, Ormö et al., 1996).

A Roger Tsien se le debe gran parte del desarrollo de la GFP; entre sus aportes más significativos se puede mencionar que ayudó a dilucidar el mecanismo de biosíntesis de la formación del fluoróforo, la estructura tridimensional de la GFP y su aporte más significativo tiene que ver con la síntesis de mutantes o variantes de la GFP. En la actualidad existe una

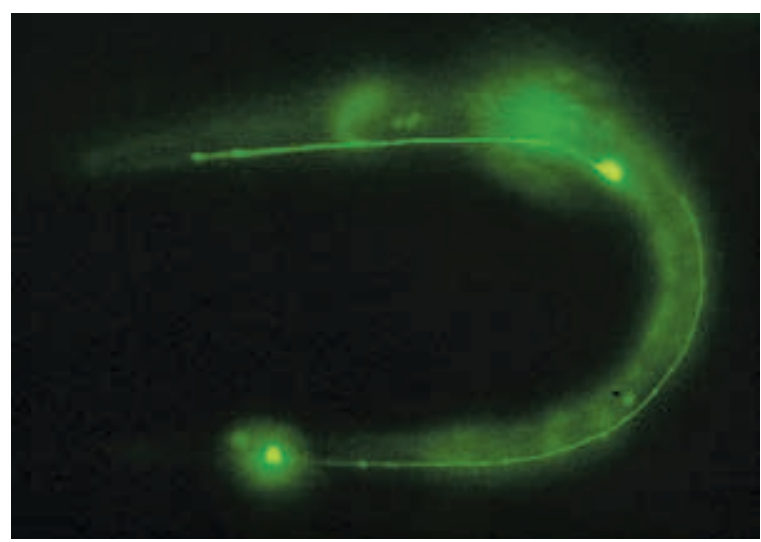

Figura 2. Expresión de la GFP en C. elegans. Fuente: Chalfie et al., 1994c. Con autorización de la revista Science y del autor.

amplia variedad de proteínas fluorescentes, cuyos colores varían desde el azul al rojo (Kremers et al., 201 I, Tsien, 1998, Welter, 2008).

\section{Bibliografía}

Alberts, B., Johnson, A., Lewis, J., Raff, M., Roberts, K. \& Walter, P. (2008). Biology Molecular of the Cell. 5 ed. New York: Garland Science.

Chalfie, M. \& Perlman, R. (1976). Studies of transplantable rat pheochromocytoma: biochemical characterization and catecholamine secretion. J. Pharmacol. Exp. Ther. 197(3): 61 5-622.

Chalfie, M., Tu, Y., Euskirchen, G., Ward, W. \& Prasher, D. (1994). Green Flourescent Protein as a Marker for Gene Expression. Science 263: 802-805

Chalfie, M. (1995). Green Fluorescent Protein. Photochem. Photobiol. 62(4): $651-656$.

Chalfie, M. (2009). GFP: Lighting up life. PNAS 106 (25): I007310080.

Cody, C., Prasher, D., Westler, W., Prendergast F. \& Ward, W. (1993). Chemical structure of the hexapeptide chromophere of the Aequorea green-fluorescent protein. Biochemistry 32: 1212-1218.

Davis, T. (2008). Profile of Martin Chalfie. PNAS I05 (5): I3931395.

Kremers, G., Gilbert, S., Cranfill, P., Davidson, M. \& Piston, D. $(201$ I). Fluorescent proteins at a glance. J. Cell Sci 124: I57160.

Lucas, J. (2009). El descubrimiento de las proteínas fluorescentes y su utilidad en la investigación biomédica (Premio Nobel de Química 2008). An. R. Acad. Nac. Farm. 75 ( I): 99- I 12.

Martín, A. (2005). Patología Quirúrgica. Madrid: Elsevier. 
McPherson, M. \& Moller, S. (2006). PCR. 2 ed. New York: Taylor \& Francis Group.

Morise, H., Shimomura, O., Morise, H., Johnson, F. \& Winant, J. (1974). Intermolecular energy transfer in the bioluminescent system of Aequorea. Biochemistry I3(12): 2656-2662.

Ormö, M., Tsien, R., Kallio, K., Gross, L., Remington, J. \& Cubitt, A. (1996). Crystal structure of the Aequorea victoria Green Fluorescent Protein. Science 273: I 392- 1395.

Prasher, D., Eckenrode, V., Ward, W., Prendergast, F. \& Cormier, M. (1992). Primary structure of the Aequorea victoria greenfluorescent protein. Gene I I 1: 229-233.
Shimomura, O. (2005). The discovery of aequorin and green fluorescent protein. J. Microscopy 217: 3-15.

Strange, K. (2006). C. elegans: Methods and Applications. New Jersey: Humana Press.

Tsien, R. (1998). The Green Fluorescent Protein. Annu. Re. Biochem. 67: 509-544.

Welter, K. (2008). La proteína verde fluorescente - una herramienta valiosa en la biomedicina. Avances en Química 3(3): 99- 103. 